\title{
Prevenção da AIDS no período de iniciação sexual: aspectos da dimensão simbólica das condutas de homens jovens
}

\author{
AIDS prevention in the period of sexual initiation: \\ aspects of the symbolic dimension of the conduct of young men
}

Bruno José Barcellos Fontanella ${ }^{1}$

Romeu Gomes ${ }^{2}$

${ }^{1}$ Departamento de Medicina, Centro de Ciências Biológicas e da Saúde, Universidade Federal de São Carlos. Rodovia Washington Luís km 235, Caixa Postal 676. 13565-905 São Carlos SP. bruno.fontanella@gmail.com ${ }^{2}$ Departamento de Ensino, Instituto Fernandes Figueira, Escola de Saúde Pública, Fiocruz.

\begin{abstract}
To acquire an in-depth grasp of the non-consistent use of condoms, an attempt was made to characterize aspects of the symbolic meanings of sexual conduct in a group of young males. Interviews with forty-two subjects whose sexual initiation occurred in the late 1990s were qualitatively assessed by an analysis of statements interpreted under the theoretical perspectives of sexual scripts and male lifestyle and values. Participants emphasized the importance of blood testing and a biographical analysis of their partners (to generate 'trust') and tended to use personal criteria to assess the state of their partners' health. They established a dyadic typology of these relationships divided into "infrequent" and "steady" partners respectively, exercising two kinds of approaches to condom use, namely prevention of AIDS-STD and pregnancy on the one hand and only for pregnancy prevention on the other. The narratives seem to result, among other factors, from a biomedical approach to aspects of their sex lives and a desire for a stable and monogamous sexual-affective relationship. The important and recent changes in the intrapsychic and interpersonal sexual scripts do not seem to be currently accompanied by equally profound changes in cultural scripts or male lifestyle and values.
\end{abstract}

Key words AIDS, Health conduct, Adolescent behavior, Sexuality, Self-care, Masculinity
Resumo Para aprofundar a compreensão sobre o uso não consistente do preservativo, objetivou-se caracterizar aspectos das significações simbólicas das práticas sexuais de jovens do sexo masculino. Entrevistas de 42 sujeitos, cujas iniciações sexuais começaram no final dos anos 90, foram abordadas qualitativamente por meio de análise de enunciados e interpretadas sob as perspectivas teóricas dos roteiros sexuais e do habitus masculino. Eles enfatizaram a importância de exames sorológicos e da análise biográfica das parceiras (para gerar "confiança") e tenderam a utilizar uma semiotécnica não fundamentada para avaliar o estado de saúde delas. Estabeleceram uma tipologia diádica: parcerias "não fixas" e "fixas", exercitando respectivamente dois tipos de roteiros quanto ao uso do preservativo: para prevenção de AIDS-DST e gravidez ou somente para prevenir gravidez. As narrativas resultariam, dentre outros fatores, de um processo de biomedicalização de aspectos de suas sexualidades e de anseios de relacionamentos afetivo-sexuais estáveis e monogâmicos. Entre os participantes, as importantes e recentes mudanças nos roteiros sexuais intrapsíquico e interpessoal não parecem ser, por ora, acompanhadas de mudanças igualmente profundas nos roteiros culturais ou de habitus masculino.

Palavras-chave AIDS, Conduta de saúde, Comportamento do adolescente, Sexualidade, Autocuidado, Masculinidade 


\section{Introdução}

O primeiro caso de AIDS na população jovem brasileira foi notificado em 1982 e, até junho de 2010, 66.751 casos entre pessoas de 13 a 24 anos haviam sido notificados. Desses, cerca de $80 \%$ ocorreram na faixa entre 20 e 24 anos e $56 \%$ entre homens ${ }^{1}$. Embora a taxa de incidência de casos notificados entre os jovens mantenha-se em patamares aproximados ${ }^{1}$, constatou-se desde o início da epidemia uma tendência de aumento na proporção da categoria "exposição sexual" ao HIV entre os rapazes que recebem este diagnóstico ${ }^{2}$.

Os jovens brasileiros mostram, via de regra, um alto nível de conhecimentos acerca dos modos de transmissão do HIV e, se comparados com outras faixas etárias, são os que mais usam o preservativo em todas as situações. Apesar disso, estudos empíricos ainda atestam também entre eles uma alta prevalência de práticas de risco para a transmissão de patógenos relacionados às DST, como o uso não consistente do preservativo (isto é, o não uso em todas as relações sexuais $)^{3-8}$.

Este artigo apresenta um dos produtos analítico-interpretativos de um estudo cujo objetivo geral foi compreender os sentidos atribuídos por homens jovens à sexualidade masculina e aos cuidados de saúde no campo da sexualidade9. Sua premissa básica foi de que esses sentidos são influenciados por fatores multifacetados e complexos que dariam a forma dos discursos sobre a sexualidade e cuidados preventivos.

No presente texto, são reportados os resultados referentes a um dos objetivos específicos: caracterizar aspectos dos significados simbólicos psicoculturais que ajudam a conformar os roteiros sexuais desenvolvidos quando da instauração das iniciações sexuais, focalizando especificamente os que estariam relacionados ao uso ou não uso do preservativo. A hipótese foi de que tais sentidos não seriam configurados primordialmente a partir de fatores pontuais, por mais influentes que pudessem ser, como aqueles representados pelas campanhas ou outras ações educativas sobre saúde sexual. Outros fatores da dinâmica psicocultural contribuiriam mais decisivamente para as condutas sexuais relacionadas ao uso ou não uso do preservativo, contrapondo-se à racionalidade veiculada nas campanhas.

O marco teórico utilizado serviu-se da noção de habitus, em particular do habitus masculino, tal como desenvolvida por Pierre Bourdieu ${ }^{10}$ uma estrutura de prescrições e regras sociais incorporadas pelos indivíduos que possibilita a reprodução inconsciente de certas práticas. En- tretanto, o habitus funciona, ao mesmo tempo, como uma matriz que permite a esses mesmos indivíduos perceber, classificar, avaliar ou, numa palavra, estruturar seus costumes.

A perspectiva teórica serviu-se também da teoria dos roteiros sexuais, desenvolvida com o protagonismo de John Gagnon ${ }^{11}$ a partir da transição das décadas de 60 e 70 . Roteiros sexuais são concebidos como um conjunto de elementos simbólicos ligados à sexualidade que estrutura uma sequência de condutas organizadas, nomeia e descreve as qualidades dos atores envolvidos, dá significados a estados internos, indica os motivos do comportamento e decodifica novas situações.

As visões dos dois sociólogos se aproximam à medida que habitus e roteirização cultural podem, ambos, serem utilizados para compreender como se processam as mudanças e as permanências do "sistema de esquemas interiorizados que permitem engendrar todos os pensamentos, as percepções e as ações característicos de uma cultura"12 em função, particularmente, das variadas "instruções culturais sobre a sexualidade" 13 a que as pessoas estão expostas, mesmo que não evidentes de forma imediata ou consciente.

A investigação foi aprovada pelo Comitê de Ética em Pesquisa com Seres Humanos da instituição a que o segundo autor se filia.

\section{Métodos}

Um conjunto de narrativas de jovens do sexo masculino, obtidas por meio de entrevistas individuais, foi abordado qualitativamente ${ }^{14}$. A ideia foi gerar elementos que reconstruíssem, sob a ótica reflexiva dos agentes sociais envolvidos, os conjuntos de atitudes, valores, crenças e acontecimentos psicossociais subjacentes às suas falas e reuníveis sob a rubrica "iniciações sexuais", que na atualidade ocorrem tipicamente ao longo da segunda década de vida nos países de cultura ocidental ${ }^{15}$. As intenções, motivações e ações desses agentes, assim como as circunstâncias têmporo-espaciais dos contextos por eles narrados, foram considerados elementos de seus sistemas simbólicos psicoculturais ${ }^{16}$ passíveis de serem compreendidos e interpretados.

As narrativas foram coletadas a partir de uma questão que reproduziu o slogan da campanha do Ministério de Saúde brasileiro realizada durante o período do carnaval de 2008 e do Dia Mundial de Luta Contra a Aids do ano anterior, apresentada a todos os participantes nos mesmos termos: Qual é a sua atitude na luta contra a aids? 
Os dados foram coletados no primeiro semestre de 2009, por meio de entrevistas individuais realizadas em locais escolhidos pelos entrevistados, por entrevistadores da mesma faixa etária que eles, com formação em ciências humanas e depois de capacitados para este tipo de entrevista. Foram asseguradas condições de privacidade e anonimato aos participantes.

$\mathrm{O}$ processo de amostragem intencional incluiu sucessivamente sujeitos em número suficiente para que houvesse reincidência e "saturação" de sentidos ${ }^{17,18}$, viabilizando discussões empiricamente fundamentadas. Adotou-se a estratégia de amostragem de "universos familiares"19,20, em que pessoas conhecidas do pesquisador indicam outras para participarem da pesquisa e estas, por sua vez, fazem novas indicações. Os sujeitos do estudo foram homens jovens de uma mesma geração, pois nasceram numa mesma época e compartilharam um mesmo cenário sociocultural ${ }^{21}$. Por ocasião do trabalho de campo, todos eram moradores da cidade do Rio de Janeiro (RJ), Brasil.

Foram incluídos jovens nascidos aproximadamente na segunda metade da década de 1980, no intervalo etário de 18 a 25 anos à época das entrevistas, e que tiveram suas iniciações sexuais a partir do final dos anos 90. Tal critério de inclusão se deveu ao fato de que, nesse período, e ao longo da infância dos entrevistados, várias campanhas de prevenção da AIDS foram empreendidas. Dois subconjuntos de participantes foram compostos com a intenção de se observar se os resultados tendiam ou não a se diferenciar conforme a escolaridade.

Também foram coletadas informações objetivas sobre as sexualidades dos participantes e algumas informações sociodemográficas. Elas não foram submetidas a uma análise quantitativa e figuram neste estudo, de forma descritiva, apenas para servir de cenário para a análise qualitativa empreendida.

As transcrições integrais das entrevistas foram analisadas e interpretadas a partir de uma adaptação da técnica de análise de enunciação ${ }^{17,22}$, em que as proposições contidas nas narrativas foram tomadas como partes de um processo de elaboração dinâmica de sentidos pessoais, expressos em palavras e frases. Nas condutas relatadas, considerou-se que poderiam estar atuantes desejos, constrangimentos e resistências psicológicas ante os conflitos vivenciados quanto aos temas pesquisados.

Depois de uma familiarização com as transcrições, os achados foram circunscritos em cate- gorias, de acordo com a identificação de possíveis núcleos de sentido nos enunciados relativos aos objetivos perseguidos. Uma atenção constante aos pormenores do corpus procurou garantir validade interna desses achados, que em seguida foram discutidos a partir dos marcos teóricos previstos ${ }^{10,11}$.

\section{Caracterização dos Sujeitos}

O corpus foi formado por 42 narrativas: 22 de homens jovens que cursavam o ensino superior (Grupo I, codificados com nomes fictícios iniciados com S) e outras 20, com jovens que não cursavam o ensino superior e residiam numa comunidade de classe popular (uma favela) (Grupo II, codificados com nomes fictícios iniciados com R). Os dois grupos caracterizaram-se algo distintamente, de acordo com a estratégia metodológica de trabalhar com uma amostra heterogênea quanto à escolaridade e classe socioeconômica (Tabela 1).

Tabela 1. Informações sociodemográficas referentes aos participantes das duas sub-amostras.

\begin{tabular}{|c|c|c|}
\hline $\begin{array}{l}\text { Características } \\
\text { sociodemográficas }\end{array}$ & $\begin{array}{c}\text { Grupo I } \\
(\mathrm{n}=22) \\
(\%)\end{array}$ & $\begin{array}{l}\text { Grupo II } \\
\qquad \begin{array}{c}(\mathrm{n}=20) \\
(\%)\end{array}\end{array}$ \\
\hline \multicolumn{3}{|l|}{ Idade (anos) } \\
\hline 18 & 0 & 20 \\
\hline 19 & 0 & 35 \\
\hline 20 & 0 & 0 \\
\hline 21 & 5 & 5 \\
\hline 22 & 45 & 10 \\
\hline 23 & 45 & 15 \\
\hline 24 & 5 & 10 \\
\hline 25 & 0 & 5 \\
\hline \multicolumn{3}{|l|}{ Cor autorreferida } \\
\hline Branca & 64 & 40 \\
\hline Parda & 18 & 45 \\
\hline Preta & 18 & 15 \\
\hline Amarela e indígena & 0 & 0 \\
\hline \multicolumn{3}{|l|}{$\begin{array}{l}\text { Renda familiar (salários } \\
\text { mínimos }^{*} \text { ) }\end{array}$} \\
\hline 1 a 5 & 27 & 70 \\
\hline 6 a 10 & 36 & 0 \\
\hline 11 a 15 & 23 & 0 \\
\hline Acima de 15 & 14 & 0 \\
\hline Não informou & 0 & 30 \\
\hline \multicolumn{3}{|l|}{ Empregabilidade } \\
\hline Sim & 68 & 35 \\
\hline Não & 32 & 65 \\
\hline
\end{tabular}

*Salário mínimo à época das entrevistas $=$ R \$ 415,00 
Como se observa na Tabela 2, os dois grupos também apresentaram dissemelhanças em relação às informações fornecidas sobre o uso do preservativo na primeira relação sexual. Os jovens do Grupo I, embora tenham usado frequentemente o preservativo na primeira relação, em geral informaram que não o fizeram na última algo que não se repetiu no Grupo II. Apesar de essas informações objetivas apontarem diferenças, várias homologias foram constatadas entre os dois grupos, ressaltando-se que tais homologias só ganharam maior visibilidade a partir de uma perspectiva analítica de cunho qualitativo.

\section{Resultados}

Primeira categoria de resultados: ênfase em "exames preventivos" e "periódicos"

Uma ideia prevalentemente expressa pelos participantes versou sobre os diferentes tipos de tecnologias biomédicas atualmente disponíveis. Ainda que não necessariamente tivessem acesso a essas tecnologias em seus cotidianos, mencionaram-nas como compondo os meios que previnem as pessoas contra doenças. Referiram-se aos "exames de sangue preventivos" e "periódicos" (Sandro e Samir) e mencionaram "o famoso check-up" (Sabino) e "ter que estar sempre se cuidando" (Sabino e Sérgio); para isso, estariam "sempre procurando cuidados médicos" (Sabi-

Tabela 2. Informações sobre sexualidade sociodemográficas referentes aos elementos pesquisados das duas sub-amostras.

\begin{tabular}{lcc}
\hline \multicolumn{1}{c}{ Informações } & $\begin{array}{c}\text { Grupo I } \\
(\mathbf{n = 2 2}) \\
(\%)\end{array}$ & $\begin{array}{c}\text { Grupo II } \\
(\mathbf{n}=\mathbf{2 0}) \\
(\%)\end{array}$ \\
\hline 1a relação sexual planejada & & \\
Sim (= não incidental) & 18 & 32 \\
Não (= incidental) & 73 & 68 \\
$\quad$ Não informou & 9 & 0 \\
Uso de preservativo & & \\
na 1a relação sexual & & \\
Sim & 86 & 47 \\
Não & 9 & 53 \\
Não informou & 5 & 0 \\
Uso de preservativo & & \\
na última relação sexual & & \\
Sim & 32 & 60 \\
Não & 64 & 35 \\
Não informou & 4 & 5 \\
\hline
\end{tabular}

no), o que por vezes traduzir-se-ia em submeter-se a exames laboratoriais:

Depois do carnaval, eu fiz um check-up geral, como se costuma chamar. Nesses quatro anos que tivemos juntos ela também fazia exames [...] acredito que ela continue se cuidando [...] Pretendo passar por isso [conjunto de exames] de novo, com a consciência tranquila de que eu estou me cuidando e de que não há nada de errado. (Radamés)

Tal modelo preventivista de sexualidade pareceu preponderar nos raciocínios: mencionaram a possibilidade de "exames pós-sexo" (Samir) e procurar "manter algum controle" sobre a saúde, realizando testes sorológicos "umas três ou quatro vezes por ano" (Saul).

Não se sabe a que condutas efetivamente tomadas corresponde esta ênfase discursiva. Talvez viessem restringindo seus comportamentos a medidas mais prosaicas, como às aludidas "assepsia e higiene das partes íntimas" (Sérgio) ou a "um banho, três vezes ao dia" (Rufino), medidas que se contraporiam à "higiene precária" (Silas), cuja solução poderia passar pelos "produtos de limpeza especiais pra mulher” (Sebastião).

No caso de não efetivarem o mencionado controle laboratorial, pareceram vivenciar certo mal-estar por não fazê-lo, considerando-se em débito por não corresponderem ao cuidado ideal que, em alguns relatos, correspondeu a uma atenção especializada e focalizada no aparelho gênito-urinário, especificamente citado por alguns participantes com nível superior de escolaridade:

Realmente não procuro, por exemplo, um especialista em urologia para me cuidar, como as mulheres têm em relação ao ginecologista. [Saulo]

Segunda categoria de resultados: avaliação biográfica da parceira ("sua confiança aumenta, seu cuidado diminui")

Os relatos permitiram inferir que os entrevistados procuram proceder a uma análise biográfica das mulheres com quem se relacionam, buscando reconhecer, dentre as potenciais parceiras, quais seriam as que não estão nem aí (Rufino) ou as que teriam uma vida sexual muito movimentada (Sandro). Para isso, avaliariam todos os parâmetros daquela pessoa (Sabino) que possam se constituir, para eles, em alertas indicadores da conveniência de sexo com preservativo. Conhecer (ao menos supostamente) essas histórias pregressas conferir-lhes-ia certa tranquilidade inicial no exercício de práticas sexuais e, a partir daí (Sabino), escolhas que consideram ponderadas acerca dos cuidados práticos: 
Você sabe também o proceder da pessoa, às vezes a gente já conhece uma que... pá, já são história da galera, 'ah, essa garota aí faz bacanal e não usa proteção'. Aí, tu também, 'vou, mas vou de camisinha', tu não deixa de ir. (Randal)

A questão de "conhecer" ou "não conhecer" certas particularidades biográficas esteve constantemente presente nas narrativas, parecendo tratar-se também de uma busca de indícios sobre qual o padrão atitudinal esperado da pessoa com quem se relaciona (por exemplo, a possibilidade de traição):

Prevenir é saber com quem você vai ficar, é camisinha, é tudo [...] porque você não sabe quem é quem. (Radamés)

A questão da "confiança" na potencial parceira sobressaiu-se tanto em razão da frequência com que este tipo de enunciado foi proferido quanto em função de sua marcante valoração em meio às outras estratégias do arsenal preventivo cotidianamente utilizado pelos participantes. Segundo se depreendeu dos relatos, procuram avaliar idiograficamente o quesito "confiabilidade" a partir de indícios biográficos e de elementos supostamente caracterizadores da personalidade da parceira pretendida. Relataram esforços para descobrir sinais indicativos de estabilidade comportamental e de capacidade de assumir compromissos, ocorrendo isto mesmo quando diantes de envolvimentos sexuais circunstanciais:

Quando começava a sair com a pessoa e via que se dedicava, aí sim, eu transava sem camisinha. [Samuel]

Conheci ela, não tinha nenhuma doença, confio nela, sei que não me trai com outra pessoa, não pegaria doença. Então, não me preocupo. [Serafim]

Ele [um amigo] vai ter um filho agora. Ele fala abertamente 'cara, eu transo sem camisinha porque eu confio na minha mulher, eu faço relação, eu tenho relação sexual com ela faz mais de cinco anos, vai fazer seis anos, porque eu transaria com camisinha com ela?' (Randal)

De modo geral e preponderantemente, foram percebidas nas narrativas um anseio por relações afetivo-sexuais que se mostrassem compromissadas, estáveis e exclusivas, ao menos por algum período de tempo:

A última vez a gente transou sem camisinha [foi] porque a gente tinha uma relação de três anos. [...] Tento confiar, sei que a gente não vai botar a mão no fogo por ninguém, a gente tem que confiar no nosso taco, eu confiei nela, mas não tive problema nenhum. (Ramon)

Relações de confiança recíproca pareceram compor o ideal dos envolvimentos emocionais, sendo vistas como elaborações interpessoais de mais longo prazo e que, no dizer de um entrevistado, devem ser constantemente construídas (Sabino). A escolha do uso ou não uso do preservativo decorreria do resultado subjetivamente aferido desta "construção", dentro do continuum de possibilidades existentes:

Quanto maior a confiança no parceiro, menos cuidado você toma em relação à sua saúde, à medida que a sua confiança aumenta, seu cuidado diminui. (Serafim)

Entretanto, embora confiar seja percebido como crucial, a efetividade do caráter absoluto dessa estratégia foi questionada pelos próprios participantes (confiança, na verdade, não existe... é uma dedução, do tipo da pessoa, da sua personalidade - Serafim) e, em vista desta relativização, tornar-se-iam necessários outros movimentos geradores da sensação de segurança. Assim, a decisão sobre o uso ou não uso do preservativo, em uma relação sexual específica, decorreria também de outros tipos de julgamentos sobre a parceira pretendida. Ao final desse processo avaliativo, tais parcerias se dividiriam basicamente em "fixas" e "não fixas", nos termos utilizados pelos próprios entrevistados e conforme comentado a seguir.

\section{Terceira categoria de resultados: dois tipos de parceira sexual, "fixa" e "não fixa"}

Os enredos desenvolvidos foram predominantemente heterossexuais e não parecem ser percebidas pelos narradores limitações apriorísticas à efetivação de relações sexuais, exceto aquelas decorrentes das interações bipessoais cotidianas, como não desejar, não querer e o não aceitar ter relações com uma pessoa específica. Típicas limitações apriorísticas, comuns noutras culturas ou para outras gerações, mas inexistentes nas narrativas, seriam a falta de acesso a parceiras sexuais por imposições doutrinárias religiosas ou por questões morais entre as famílias. Igualmente não fariam parte dos enredos, a julgar pelos relatos obtidos, as relações sexuais com prostitutas em que, a priori, as questões de escolha e aceitação não seriam aplicáveis. A expectativa dos entrevistados, ao contrário, é de haver acesso a parceiras sexuais sem maiores empecilhos (vai num lugar, conhece uma menina e se engraçaSalomão; tinha acabado de se conhecer, e lá é assim, o pessoal se conhece e na hora [já vai] se pegando, e foi no meio da rua mesmo - Randal).

Assim, à medida que parecem inexistir, para iniciar uma parceria afetivo-sexual, fortes barreiras culturais, morais ou religiosas, ou regras 
institucionais a serem rigidamente seguidas, como no casamento, impor-se-ia aos participantes a necessidade de outros tipos de balizas ordenadoras de qual tipo de interação sexual ocorrerá com essas parceiras que ainda lhes são muitas vezes estranhas, de fora de seus convívios sociais. Nestes momentos, variadas questões podem ser subitamente colocadas, exigindo uma tomada de decisão rápida e "acertada”, embora permeada de angústias:

Ela não queria. Aí falei: 'pô, a camisinha, aí...' A gente nem tinha camisinha, mas [mesmo assim] eu falei. Aí, ela: 'não, pô, sem camisinha mesmo'. Aí eu pensei bem, aí eu olhei, na hora, pô, na hora, né? Na hora agá eu errei essa coisa [...] Ela não queria, ela tava cheia de vergonha, eu acho que ela pensou que se eu parasse pra botar camisinha, ofato ia atrapalhar, como ela tava meio, tipo excitada, então aí eu acho que ela deu um... pensou que ia atrapalhar ela, aí ela não deixou eu pegar, e também eu não tinha camisinha. Foi isso, por isso que aconteceu do nada, bem no quarto dela. (Rafael)

Diante de situações conflituosas e cruciais como essa, provavelmente comuns nos períodos de iniciação sexual, uma classificação entre parceiras "fixas" e "não fixas" parece servir para indicar com rapidez qual deve ser a prática sobre o uso do preservativo a ser seguida. O Quadro 1 condensa as características desta tipologia diádi$\mathrm{ca}$, conforme as principais oposições enunciadas nas narrativas.

Quadro 1. Tipologia diádica das parcerias sexuais nos discursos dos participantes.

\begin{tabular}{|c|c|}
\hline Parceria "fixa" & Parceria “não fixa”(casual) \\
\hline \multicolumn{2}{|c|}{ As mulheres } \\
\hline $\begin{array}{l}\text { "Parceira, namorada, esposa, ficante, seja lá o que } \\
\text { for" }\end{array}$ & $\begin{array}{l}\text { "Mulher da roda", "da rua", "da pista", "as outras", } \\
\text { "mulherzinha" }\end{array}$ \\
\hline Pessoa "certa" & "Mandada" \\
\hline $\begin{array}{l}\text { Com biografia (supostamente) conhecida (história } \\
\text { das atitudes) }\end{array}$ & Com biografia desconhecida \\
\hline "Não é mulher pra se fazer isso" & "Mulher pra se fazer isso" \\
\hline \multicolumn{2}{|c|}{ O relacionamento } \\
\hline $\begin{array}{l}\text { Planos individuais convivendo com planos do } \\
\text { casal (amor romântico) }\end{array}$ & Planos individuais somente \\
\hline $\begin{array}{l}\text { Relação ideal almejada: monogâmica e de } \\
\text { cuidados mútuos }\end{array}$ & "Parceira arrumada" \\
\hline $\begin{array}{l}\text { Ideal de não traição, "relacionamento sério", } \\
\text { "realmente gosto", relação emocional de } \\
\text { confiança }\end{array}$ & Somente práticas sexuais (em geral, penetrativas) \\
\hline Gera "tranquilidade" & Sexo é "perigoso" \\
\hline "Sexo com cuidados" & Sexo somente \\
\hline Produto de "acerto" & Produto de errância (nomadismo afetivo-sexual) \\
\hline Seletividade na escolha da parceira & $\begin{array}{l}\text { Escolha da parceira com elementos de } \\
\text { impulsividade }\end{array}$ \\
\hline \multicolumn{2}{|c|}{ O preservativo } \\
\hline Resistências à incorporação à rotina da vida sexual & $\begin{array}{l}\text { Incorporado à rotina (embora com lapsos, por } \\
\text { exemplo, nas intoxicações alcoólicas ou diante de } \\
\text { demandas emocionais emergenciais, como pressões } \\
\text { para não usar) }\end{array}$ \\
\hline Função sobretudo contraceptiva & Função contraceptiva e de proteção contra DST-AIDS \\
\hline Nem sempre usado & Usado com mais frequência \\
\hline Usado para "cuidar" do relacionamento & Usado para assegurar vida (e vida sexual) longeva \\
\hline Meta de prescindir do uso & Sem perspectiva de não usar \\
\hline $\begin{array}{l}\text { Roteiro vai além do uso (uso + 'todo um cuidado } \\
\text { com a parceira') }\end{array}$ & $\begin{array}{l}\text { Hábito do uso incorporado e associado a uma } \\
\text { semiotécnica (ingênua) de proteção }\end{array}$ \\
\hline
\end{tabular}


Relações sexuais sem preservativo com parceiras "não fixas" ou "não conhecidas" (Sandro) foram relatadas como exceções raras. Ocorrendo, gerariam receios intensos de contaminação pelo HIV. O uso do preservativo teria sido a regra nesse tipo de relação sexual fortuita e não planejada, indicando que o comportamento de portar o preservativo estaria incorporado ao cotidiano dos participantes.

Para uma parte dos entrevistados, no entanto, o contato com essas parceiras "não fixas" parece longe de ser o padrão desejado de interação sexual e faria somente parte do processo de busca por uma parceira "fixa”. Nessa trajetória o grau de fixidez ou proximidade com a parceira não é avaliado de maneira categórica (como seria "casada" ou "não casada"), mas sim dimensional. Em termos de tempo, a duração de uma relação "fixa" pode ser produto de anos de relacionamento ou de minutos:

Então você beijou aquela primeira vez. Aquela pessoa, a partir dali, você deposita confiança que ela não vai beijar outra pessoa, pelo menos ao longo dos próximos dez minutos. [Sabino]

Parcerias "fixas" comporiam, então, um conjunto extenso de possibilidades relacionais. Caracterizar-se-iam pela avaliação (pouco precisa) de haver certas regularidades e ordenamentos. Corresponderiam a relações estabelecidas depois de rolar um sentimento, de ser vivido um ritual, por vezes com uma amiga, ou preferencialmente com uma pessoa certa (Samir), com a garota da minha vida (Sebastião), com minha mulher (Rufino).

Neste tipo ideal de relacionamento, a necessidade do uso do preservativo é altamente relativizada e, quando utilizado, via de regra serviria somente a propósitos contraceptivos, mas não aos de prevenção de DST.

Quarta categoria de resultados: avaliação
do estado de saúde da parceira (“uma
olhada lá de perto... viu que não tem nada")

A distinção entre um tipo e outro de parceiras sexuais exigiria, em alguns momentos, o recurso a uma espécie de semiologia que, embora não fundamentada clinicamente, parece aos entrevistados ser suficiente para discernir o estado de saúde ou doença. Valorizaram-se observações empíricas, sobretudo visuais, em possível contraposição a abstrações mais complexas (...quando vê um problema de frente - Rufino; a AIDS é um vírus, você não consegue ver - Radamés).

Algumas menções remetem ao uso de uma "semiotécnica" difícil de ser qualificada quanto ao que estaria sob exame. Precem ser considerados alguns atributos da potencial parceira, inclusive da dimensão psicológica, mas certamente pouco específicos, operacionálizáveis ou objetiváveis:

Você vê uma pessoa assim e diz 'aquela já deve ter rodado, é rodadona' [...] Você vê às vezes uma pessoa quietinha assim, mas eu falo 'essa aí é calma', é quase zero pau. (Serafim)

A gente já sabe, só de olhar, se a mulher já é piranha, pelo jeito dela ser. (Ramon)

Um entrevistado resumiu o tipo de atributo avaliado como sendo o grau de cuidado consigo próprio que as mulheres teriam (você vê que a pessoa tem uma certa falta de cuidado... - Sérgio). Outros enunciados indicaram, também imprecisamente, que alguns valores estimados referemse à estética corporal, que exerceriam influência no juízo que se faz quanto ao risco presente, associando-os à ideia de saúde ou de cuidado com a saúde ("você fica escolhendo pela cara... se a cara é bonitinha... se ela for feia, você usa camisinha Sálvio). Durante o próprio ato sexual, pode-se empreender uma avaliação semiológica a partir de uma empiria um pouco mais objetiva, embora igualmente não fundamentada:

A primeira vai de camisinha, aí você vê que não tem nada de errado: mulher direita, não tem nada com cheiro ruim e tal... É sério, cara, não é brincadeira... Deu uma olhada lá de perto, viu que não tem nada acontecendo, tá tudo bem. Aí a segunda e a terceira, não precisa mais [de camisinha]. (Sálvio)

\section{Discussão}

Consoante aos objetivos específicos estipulados, nesta discussão será destacada a função que certos elementos dos roteiros mentais (intrapsíquicos) têm em relação aos demais níveis de roteirização utilizados pelos participantes e que culminam, ou não, com o uso do preservativo.

Constantes significações simbólicas de medos e ansiedades estiveram presentes nos relatos feitos sobre os relacionamentos afetivo-sexuais. Essas angústias não se deveriam apenas às inseguranças, em dada medida universais, presentes nas aproximações eróticas interpessoais, em particular nas primeiras etapas das iniciações sexuais ou diante de novos parceiros. Igualmente não se restringiriam ao medo da gravidez indesejada, aparentemente comum aos enredos hegemonicamente heterossexuais de diferentes épocas e sociedades nos últimos dois séculos, e repetidos nas narrativas aqui analisadas. A esses medos e angústias 
históricos parecem somar-se hoje, como produto de três décadas de epidemia, as pressões representadas pelo medo do adoecimento por AIDS.

No entanto, embora intensas, tais pressões teriam influência apenas parcial sobre as práticas sexuais efetivamente exercitadas pois, tal como se verifica para os dois subgrupos (Tabela 2) e como também constatado em outras recentes pesquisas ${ }^{3,4,7,8}$, o uso do preservativo pelos jovens continua a ser feito de forma não consistente. Infere-se, assim, que outras influências ainda mais fortes e determinantes estão presentes, resultando em duas grandes possibilidades de roterização interpessoal, adiante explicadas.

\section{Riscos, medo}

\section{e biomedicalização da sexualidade}

Os entrevistados compõem uma geração instada a considerar, desde a infância, as perturbações provocadas pela infecção, sintomática ou não, pelo HIV. Isto parece ter influenciado seus planos de vida sexual e, depois de iniciados, seus roteiros intrapsíquicos para as práticas sexuais efetivamente realizadas (roteiros interpessoais). Assim, o medo da AIDS configurou-se claramente como um dos panos de fundo cognitivos das narrativas obtidas.

$\mathrm{Na}$ instância de roteirização intrapsíquica, que compreende os planejamentos para ações futuras e os guias mentais para condutas no presente $^{13}$, a ideia de "sexualidade" caminha paralelamente, para os entrevistados, à ideia de "doença". Quando ouvem e falam em "saúde sexual", enfatizam preponderantemente a ideia de práticas biomédicas avaliativas (como os exames sorológicos), embora a incorporação de abstrações científicas sobre "contaminação" e "doenças"lhes seja aparentemente difícil. O entendimento de mecanismos e processos biopatológicos e epidemiológicos, tais como teorizados pelas ciências da saúde, fogem certamente do alcance do senso comum e os riscos de contaminação pelo HIV e de desenvolvimento da AIDS parecem configurar-se, para os participantes, como um risco moderno, no sentido de necessitar de olhos especializados da cultura científica para ser compreendido de forma abrangente ${ }^{23}$.

Saúde sexual é, então, vista por alguns participantes como cingida por exames e por outros aspectos de uma atenção eminentemente biomédica, entre eles o cuidado especializado com determinados aparelhos corporais. A já tradicional relação longitudinal das mulheres com o processo de cuidado ginecológico com seus aparelhos genitais foi vista como parte de um modelo ideal de cuidados à saúde. Algo correspondente pode passar a ser almejado também pelos entrevistados, na forma do recurso a especialistas focais, tendo o médico urologista sido mencionado, em particular pelos entrevistados com nível superior de escolaridade. Houve, no entanto, referências à ideia desses cuidados, não efetivado por nenhum deles, tendo os participantes " $S$ " expressado sentirem-se em falta com isso.

A tomar pelos relatos, ser examinado é visto como habitual para as mulheres, mas não para os homens que, antes, tenderiam a examinar o corpo feminino, inclusive com a finalidade de detectar problemas. Parece assim ocorrer uma incorporação aos roteiros sexuais de aspectos de uma episteme tipicamente médica, sendo chamativas as menções dos participantes ao exercício de uma semiologia do estado de saúde da parceira. Como descrito nos Resultados, relatou-se mesmo um simulacro de exame ginecológico durante a relação sexual (deu uma olhada lá de perto... viu que não tem nada acontecendo... - Sálvio).

Ainda quanto à incorporação da episteme médica, a postura semiológica empreendida parece estender-se a um tipo de avaliação psicopatológica, em que se procura conjecturar, a partir do exame das biografias das mulheres pretendidas e de seus comportamentos diretamente observáveis, se há elementos suficientes em suas personalidades que permitam supor estabilidade e confiança. Isto, basicamente, para inferir as chances de traição futura ou de uma vida sexual muito movimentada no passado (Sandro).

Embora tenha também havido menções de serem riscos para suas parceiras, isto foi pouco enfatizado, talvez em função das dificuldades de se colocarem na posição de infectantes, algo possivelmente denunciador, em seus imaginários, de infrações a um habitus heteronormativo. A necessidade de vigiar e controlar o corpo e a personalidade das mulheres, aparentemente engendrada pela premissa "trágica" de malignidade feminina ${ }^{10}$, estaria se valendo de uma medicalização da sexualidade: a medicina oficial e seus instrumentos biotecnológicos forneceriam os parâmetros de uma sexualidade saudável, participando da vida cotidiana dos entrevistados. Exemplos disso seriam a apologia à periodicidade de exames sorológicos e a tentativa de incorporação da episteme médica, independentemente da nulidade da eficácia da semiotécnica utilizada, atéorica e atada a uma empiria imediata.

Postula-se, assim, ocorrer uma dissonância entre o que se considera adequado, a priori, fazer 
para evitar riscos (isto é, agir conforme as informações que se têm, independentemente do nível de abstração atingido sobre elas) e o que se pode fazer (a colocação em prática desses planos de ação, confusamente fundamentados), gerando intensos conflitos que influenciam os roteiros sexuais interpessoais efetivamente realizados com as parceiras pretendidas. O medo da doença e da morte e a apreensão diante dos riscos de contaminação que não podem ser previstos com exatidão, promoveriam uma profunda adaptação das práticas instituídas nesses roteiros sexuais interpessoais.

\section{Concomitância de dois roteiros sexuais, de acordo com o "tipo" de parceira}

Como mencionado, os participantes valorizaram a questão da confiança em suas parceiras e, para isso, na tentativa de diminuir os riscos, avaliam suas biografias e seus corpos. O termo confiança e palavras correlatas foram utilizados ubiquamente e tal desejo de confiar parece parte de um pano de fundo emocional (roteiro intrapsíquico) com que se procura iniciar um relacionamento "fixo".

Há indícios no corpus de que se mantém a tendência, que parece tradicional da masculinidade nas últimas várias gerações, de diferenciar as mulheres segundo uma tipologia diádica (Quadro 1), de acordo com a pretensão de fixidez que se tenha em relação a elas, mesmo que seja um regime pensado somente para as mulheres ou uma monogamia em série para ambos os sexos. Trata-se da diferenciação entre mulheres virtuosas, casadouras e decentes (não expostas a outros homens) em contraposição às pecaminosas, não destinadas ao casamento e vadias (expostas a outros homens que são, possivelmente, também eles próprios, considerados infectantes) $)^{13,24}$. Embora permanceçam em alguns relatos, parece haver uma atenuação dos julgamentos morais imiscuidos a esses adjetivos (Quadro 1), o que pode representar a adoção, na dimensão dos roteiros intrapsíquicos, das premissas de igualdade civil entre os sexos. Entretanto, perseveram as pretensões de instituir relações compromissadas com as mulheres que seriam produtos de escolhas "certas” e que, em gerações anteriores, poderiam ser aquelas consideradas "para casamento". Persevera igualmente a localização das não destinadas ao casamento como fora do ambiente doméstico ("da rua", "da pista"), ou seja, mulheres cujos corpos se expõem a outros homens. Pela estabilidade com que é expressa, tal tipologia parece útil à compreensão dos comportamentos sexuais masculinos, já sendo utilizada em vários estudos brasileiros. Villarinho et $\mathrm{al}^{25}$, por exemplo, contrapuseram as parcerias "fixas" (esposa, companheira ou namorada) àquelas "casuais" e às "frequentes" (porém não "fixas").

No sentido do almejo de uma união matrimonial, o enredo hegemônico presente nas narrativas é não apenas heterossexual e heteronormativo, mas caracteriza-se também pelo almejo de um amor romântico ${ }^{24}$ que, embora separado da ideia de um casamento formal no futuro, valoriza fortemente a ideia de um relacionamento íntimo monogâmico e duradouro.

$\mathrm{Na}$ Figura 1 sugere-se um modelo em que dois diferentes conjuntos de roteiros intrapsíquicos e interpessoais estariam disponíveis e seriam praticados com os dois tipos possíveis de parcerias sexuais: "fixas" e "não fixas". Cada um desses roteiros levaria a consequências diferentes quanto aos objetivos do uso do preservativo. Para as parceiras "não fixas" (roteiro 2), o uso do preservativo tenderia a ser mais frequente e teria as funções tanto de evitar DST quanto a gravidez. Para as parceiras "fixas" (roteiro 1), o uso do preservativo, progressivamente menos frequente à medida que a pareceria seja considerada mais estável, destinar-se-ia exclusivamente a evitar a gravidez indesejada. Atente-se novamente, no entanto, para o caráter altamente subjetivo dessa almejada fixidez dos relacionamentos (que vai da "ficante" até a "esposa"), resultando em alto grau de imprecisão nas escolhas das práticas sexuais efetivadas.

Digno ainda de ser ressaltado é que o preservativo foi o parâmetro explicitamente mais valorizado dentre as medidas de redução de riscos. Em menor medida, mencionou-se a diminuição do número de parceiras e, ainda menos (em apenas uma narrativa), a abstinência sexual. Não foram citadas como alternativas a restrição da relação a práticas preliminares sexuais ou o sexo oral como alternativa à penetração. Tratar-se-ia de outro indício de perseveração cultural inserido no habitus masculino, qual seja, sua função sexual ativa e penetrante ${ }^{10}$.

\section{Comentários finais}

Pelo menos desde o final da década de 1990, as taxas de incidência de casos notificados de AIDS nas sucessivas coortes de jovens brasileiros mantêm-se inquietantemente estáveis, ao redor de cerca de 15 a 20 por cem mil habitantes, na faixa 


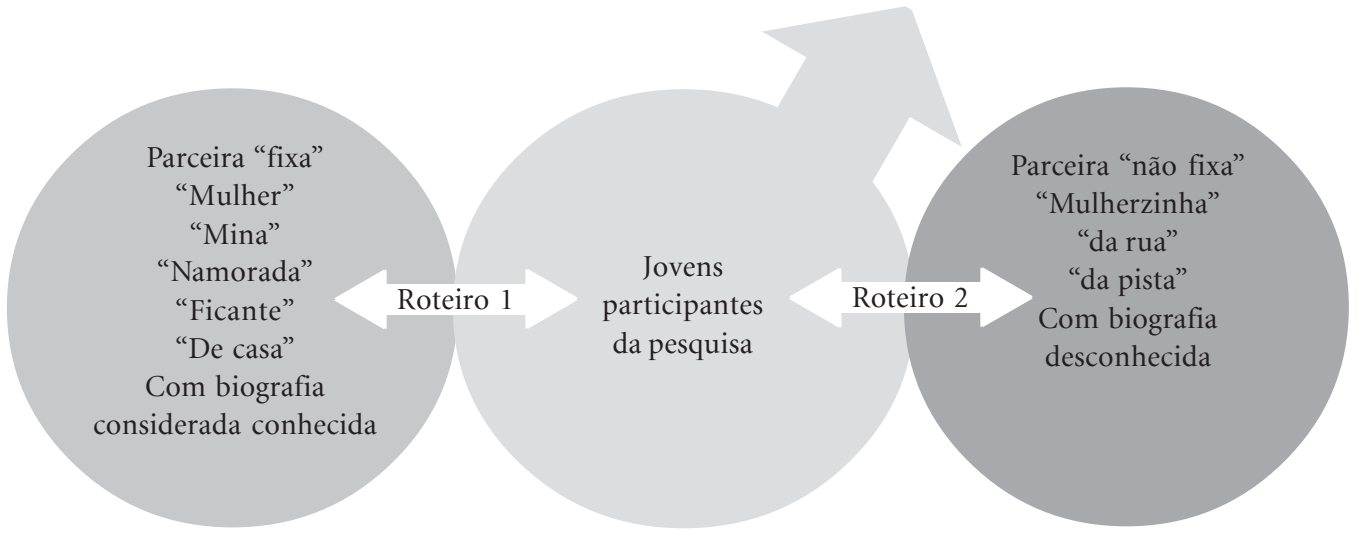

Roteiro 1 (intrapsíquico e interpessoal): Exercido junto à parceira considerada "fixa"; ideal monogâmico (mesmo que em série) e tendência ao "amor romântico"; uso do preservativo sobretudo no começo do relacionamento e, depois, uso com finalidade precipuamente contraceptiva; procura-se desenvolver "confiança". É meta do relacionamento o não uso (ou uso inconstante) do preservativo.

Roteiro 2 (intrapsíquico e interpessoal): Exercido junto à parceira considerada "não fixa"; relações eventuais com objetivo de fruição sexual; uso do preservativo com finalidade de proteção contra DST; "semiotécnica ingênua" para avaliar o estado de saúde da parceira, valorização da biotecnologia de avaliação diagnóstica. Inconstância do uso do preservativo tende a ocorrer quando da intoxicação alcoólica ou outras substâncias e diante de "emergências" emocionais nos relacionamentos interpessoais (demandas interpessoais com que não se consegue lidar durante o ato sexual).

Elementos de roteirização cultural comuns aos dois roteiros, representando possíveis permanências do habitus masculino: corpo feminino a priori infectante e "maléfico" (mulher precisa ser controlada e mostrar-se confiável ou "limpa"); ênfase em relações heterossexuais e penetrativas.

Figura 1. Dois tipos modelares de roteirização sexual, implementados simultaneamente pelos participantes da amostra estudada.

etária entre os 20 e 24 anos. A questão continua, portanto, a configurar-se como como um problema para a saúde pública brasileira, a despeito de avanços constatados nos conhecimentos, atitudes e práticas preventivas desses jovens.

A hipótese de que a complexa dinâmica psicocultural vivida pelos atores sociais contribui decisivamente para as condutas sexuais (quanto ao uso não consistente do preservativo) parece ratificada, no que pese o forte enraizamento no universo cognitivo dos participantes da racionalidade veiculada pelas ações em educação sexual. Pôde-se verificar um descompasso entre os chamados roteiros sexuais intrapsíquicos em relação aos roteiros sexuais culturais, dimensão esta considerada mais próxima à do habitus masculino. Por exemplo, a "necessidade do urologista" comentada pelos participantes (ou seja, a ideia do homem como objeto específico de atenção médica, uma novidade recente em termos cognitivos) se contrapõe ao habitus masculino vigilante sobre a "malignidade" feminina - nos termos de
Pierre Bourdieu -, correspondendo à permanência cultural de uma tradição presente há pelo menos dois séculos e que coloca a mulher como objeto de atenção. Assim, a adoção pelos entrevistados das premissas de igualdade civil entre os sexos ocorre paralelamente à manutenção de uma tipologia diádica que desqualifica parcela significativa das mulheres. Do mesmo modo, a adoção da ideia de legitimidade da episteme médica voltada para os homens contrasta com a prática desta mesma no próprio exercício da sexualidade, com tendência ao controle semiológico da saúde das mulheres. Tais contrapontos parecem atestar que mudanças nos roteiros intrapsíquicos e interpessoais não correspondem de imediato a mudanças profundas nos roteiros culturais, mais inertes.

As três instâncias de roteirização sexual postuladas por John Gagnon ${ }^{11,13}$ parecem passar por adaptações à situação aterrorizante, em termos psicoculturais, representada pela epidemia de AIDS. Medos constantes relacionados à infecção 
e à doença permeariam o processo de iniciação sexual dos entrevistados, que nasceram durante a emergência da epidemia e viveram suas primeiras experiências sexuais sob as influências de campanhas preventivas. Tratar-se-ia de uma roteirização intrapsíquica reativa a este medo, que influenciaria sobretudo os modos de compreensão dos agentes sociais sobre suas práticas sexuais e de autocuidado, mas nem sempre influenciando as práticas realmente efetivadas, passíveis de mudanças somente, talvez, no decurso de gerações. Os elementos cognitivos de tal roteirização reativa não pareceram diferenciar-se substancialmente nos dois grupos de jovens entrevistados, sendo as diferenças de frequências dos roteiros interpessoais efetivados pelos dois grupos (retratados, quanto ao uso do preservativo, na Tabela 2) talvez devidas apenas às diferenças de oportunidades de relações sexuais; ou seja, o roteiro 2, com parceiras não fixas, sendo mais frequente entre os jovens do grupo II, de mais baixa escolaridade.

Como em qualquer pesquisa qualitativa, as interpretações feitas no presente texto podem ser consideradas válidas internamente à amostra de sujeitos abordada, à medida que se procurou pautá-las empiricamente. A validade externa dessas interpretações poderá ser auferida ao longo do tempo, no diálogo que se seguirá com a comunidade científica e com o próprio universo populacional estudado.

\section{Colaboradores}

R Gomes responsabilizou-se pela coleta de dados. BJB Fontanella e R Gomes trabalharam juntos em todas as demais etapas da pesquisa, incluindo a redação do presente relatório. 
Referências

1. Brasil. Ministério da Saúde (MS). Versão preliminar: $26^{a}$ a $52^{a}$ semanas epidemiológicas - julho a dezembro de 2009. 01 a $26^{\mathrm{a}}$ semanas epidemiológicas - janeiro a junho de 2010. Boletim Epidemiológico AIDS-DST 2010; 7(1):1-21.

2. Brasil. Ministério da Saúde (MS). 27a à 52a semanas epidemiológicas - julho a dezembro de 2006. 01 à 26a semanas epidemiológicas - janeiro a junho de 2007. Boletim Epidemiológico AIDS-DST 2007; 4(1):146.

3. Berquó E, Barbosa RM, Lima LP. Uso do preservativo: tendências entre 1998 e 2005 na população brasileira. Rev Saude Publica 2008; 42(Supl. 1):34-44

4. Camargo BV, Botelho LJ. Aids, sexualidade e atitudes de adolescentes sobre proteção contra o HIV. Rev Saude Publica 2007; 41(1):61-68.

5. Fernandes JCL. Evolução dos conhecimentos, atitudes e práticas relativas ao HIV/Aids em uma população de favela do Rio de Janeiro. Cad Saude Publica 1998; 14(3):575-581.

6. Geluda K, Bosi MLM, Cunha AJLA, Trajman A Quando um não quer, dois não brigam: um estudo sobre o não uso constante de preservativo masculino por adolescentes do Município do Rio de Janeiro, Brasil. Cad Saude Publica 2006; 22(8):1671-1680.

7. Brasil. Ministério da Saúde (MS). Secretaria de Vigilância Saúde, Programa Nacional de DST e Aids. Pesquisa de Conhecimento Atitudes e Práticas na População Brasileira de 15 a 54 anos, 2004. Brasília: MS; 2005.

8. Brasil. Ministério da Saúde (MS). Secretaria de Vigilância Saúde. Programa Nacional de DST e Aids. Pesquisa de Conhecimentos, Atitudes e Práticas relacionada às DST e Aids da População Brasileira de 15 a 64 anos de idade, 2008 [apresentação na Internet]. [S/D]. [acessado 2011 mar 22]. Disponível em: http:/ /www3.aids.gov.br/publicacao/pcap-2008

9. Gomes R. Masculinidade e Cuidados e Saúde. Projeto de Pesquisa vinculado a Bolsa de produtividade apoiada pelo CNPq. Rio de Janeiro: IFF, Fiocruz; 2006.

10. Bourdieu P. A dominação masculina. 2a Edição. Rio de Janeiro: Bertrand Brasil; 2002.

11. Gagnon JH. Uma interpretação do desejo: ensaios sobre o estudo da sexualidade. Rio de Janeiro: Garamond; 2006.

12. Bourdieu P. Estrutura, habitus e prática. In: Bourdieu P, organizador. A economia das trocas simbólicas. São Paulo: Perspectiva; 2007. [1967]. p. 203-229.
13. Gagnon JH. O uso explícito e implícito da perspec tiva da roteirização nas pesquisas sobre a sexualidade. (1991). In: Gagnon JH. Uma interpretação do desejo: ensaios sobre o estudo da sexualidade. Rio de Janeiro: Garamond; 2006. p. 211-268.

14. Denzin NK, Lincoln YS. Introduction: the discipline and practice of qualitative research. In: Denzin NK, Lincoln YS. Handbook of qualitative research. London: Sage Publications; 2000. p. 1-29.

15. Bozon M. Sociologie de la sexualité. $2^{\text {nd }}$ Édition. Paris: Armand Colin; 2009.

16. Jovchelovitch S, Bauer MW. Entrevista narrativa. In: Bauer MW, Gaskell G, organizadores. Pesquisa qualitativa com texto, imagem e som: um manual prático. Petrópolis: Vozes; 2002. p. 90-113.

17. Minayo MCS. O desafio do conhecimento: pesquisa qualitativa em saúde. São Paulo: Hucitec; 2007.

18. Fontanella BJB, Ricas J, Turato ER. Amostragem por saturação em pesquisas qualitativas em saúde: contribuições teóricas. Cad Saude Publica 2008; 24(1): 17-27.

19. Vaitsman J. Flexíveis e plurais: identidade, casamento e família em circunstâncias pós-modernas. Rio de Janeiro: Rocco; 1994.

20. Velho G. Individualismo e cultura. Rio de Janeiro: Zahar; 1981.

21. Domingues JM. Gerações, modernidade e subjetividade coletiva. Tempo soc 2002; 14:67-89.

22. Bardin L. Análise de conteúdo. Lisboa: Edições 70; 1979.

23. Beck U. Sociedade de risco. São Paulo: Editora 34; 2010.

24. Giddens A. A transformação da intimidade: sexualidade, amor e erotismo nas sociedades modernas. São Paulo: Editora da Unesp; 1993.

25. Villarinho L, Bezerra I, Lacerda R, Latorre MRDO, Paivac V, Stalld R Hearstd N. Caminhoneiros de rota curta e sua vulnerabilidade ao HIV, Santos, SP. Rev Saude Publica 2002; 36(4):61-67.

Artigo apresentado em 06/04/2011

Aprovado em 31/07/2011

Versão final apresentada em 17/10/2011 